\title{
DETERMINATION OF CAPSAICIN CONTENT AND PUNGENCY LEVEL OF DIFFERENT FRESH AND DRIED CHILLI PEPPERS
}

\author{
Popelka, P. ${ }^{1}$, Jevinová, P. ${ }^{1}$, Šmejkal, K. ${ }^{2}$, Roba, P. $^{1}$ \\ ${ }^{1}$ University of Veterinary Medicine and Pharmacy in Košice \\ Slovakia \\ ${ }^{2}$ University of Veterinary and Pharmaceutical Sciences in Brno \\ Czechia \\ peter.popelka@uvlf.sk
}

\section{ABSTRACT}

One of the traditional plants that have so many pharmacological effects is chilli fruit (Capsicum sp.) that belong to the family Solanaceae. Around the world, five varieties of Capsicum are known, i.e., C. annuum, C. frutescens, C. chinense, C. baccatum, and C. pubescens. Chilli peppers are known for causing the sensation of heat or burning when consumed. The heat sensation is incited by the type and the amount of a group of capsaicinoids; the alkaloids found only in chilli pepper pods. A widely used heat measurement of chilli peppers is the SHU (Scoville Heating Unit). This measurement is the highest dilution of a chilli pepper extract at which heat can be detected by a taste panel. Nowadays, the Scoville organoleptic test has been largely replaced by chromatographic methods which are considered to be more reliable and accurate. The HPLC (High Pressure Liquid Chromatography) method was used for the determination of capsaicin content in various fresh and dried peppers from the genera $C$. chinense. Currently, based on the results of HPLC, the hottest pepper has been Bhut Jolokia, fol- lowed by Habanero Red Savina and Habanero Yellow etc. The content of capsaicin in dried chillies is 7-10 times higher compared to fresh ones.

Key words: Bhut Jolokia; capsaicin; chilli peppers; Habanero; HPLC

\section{INTRODUCTION}

For a long time hot pepper fruit has been known all over the world as a delicious spice with a characteristic smell and taste. It is used for preparing spicy sauces and also it is very popular in Mexican and Asian cuisines. The value of hot pepper consists in its sensorial attributes, such as colour, spiciness and flavour [15]. Chilli peppers and their isolated constituents including capsaicinoids are appreciated because of their beneficial therapeutic effects, including antioxidants, anti-inflammatory, anticancer, antimicrobial and positive immunomodulatory effects.

Capsaicinoids are derivates of benzylamin. Differences within their structure depend mainly on their acyl moi- 
eties, and three structural elements are involved: first of all, the length of the acyl chain (C8-C13), then the way it terminates (linear, iso or anteiso-series), and the presence or absence of unsaturation at the $\omega-3$ (capsaicin type) or $\omega-4$ carbon atom (homocapsaicin type I and II) [6]. Capsaicin, a homovanillic acid derivative (8-methyl-N-vanillyl6-nonenamide), is an active component of the red pepper. The level of the capsaicin in a seasoned pepper is around $0.025 \%$, and in the hot pepper around $0.25 \%$ (9). Capsaicin represents $69 \%$ in the group of capsacinoids; dihydrocapsacinoids with $22 \%$; nordihydrocapsacinoids with $7 \%$; and homocapsaicin and homohydrocapsaicin represents only $1 \%$ in the group of capsaicinoids. Capsaicin and dihydrocapsaicin is approximately twice as pungent as nordihydrocapsaicin and homocapsaicin and they are responsible for the hotness of the pepper. The pungency of capsaicinoids and pepper containing preparations can be expressed in Scoville Heat Units (SHU) and the human palate can detect it even diluted in a 1:17000000 ratio. A widely used heat measurement of chilli peppers is the SHU [16]. This measurement is the highest dilution of a chilli pepper extract at which heat can be detected by a taste panel. Nowadays, however, the Scoville organoleptic test has been largely replaced by chromatographic methods which are considered to be more reliable and accurate [13].

The capsaicinoids have evolved in chilli peppers as a defence mechanism against mammalian predators; nevertheless, this trait is an important fruit quality attribute and one of the most important reasons chilli peppers are consumed. It is an extraordinarily versatile agent, and its use is ranging, in the fields from pharmaceutical purposes and nutrition (seasoning) to chemical weapons. It has been used as an analgesic against arthritis pain and inflammation [5]. It has also been reported to show anticancer effect [12] and to be active against neurogenic inflammation (burning and stinging of hands, mouth and eyes) [17]. The latter property is the basis for the use of capsaicin in defensive pepper sprays. Capsaicin has also been reported to show protective effects against high cholesterol levels and obesity [10]. Capsaicin and other members of the capsaicinoids group produce a large number of physiological and pharmacological effects on the gastrointestinal tract, the cardiovascular and respiratory systems, as well as the sensory and thermoregulation systems.

The amount of capsaicinoids in a chilli pepper pod is dependent on the genetic makeup of the plant and the en- vironment where it is grown [21]. The amount of capsaicin in a given variety can vary depending on the light intensity and temperature at which the plant is grown, the age of the fruit, and the position of the fruit on the plant. Chilli peppers must be harvested at an appropriate degree of development in accordance with the criteria proper to the variety and the area in which they are grown.

\section{MATERIALS AND METHODS}

Six Habanero chilli varieties (Habanero Red Savina (HRS), Habanero Yellow (HY), Habanero Maya Red (HMR), Habanero Tasmania (HT), Habanero Paper Latern (HPL), Habanero Red (HR) ), and a Bhut Jolokia variety (BJ) have been used in our experiments. The experiments have been started by buying seeds, then sowing, germination, transplanting gradually and care of mature plants, including adaptation of climatic conditions and fertilization in the greenhouse of the University of Veterinary Medicine and Pharmacy in Košice. After harvesting the ripe fruits collected from at least three plants, they were stored in a refrigerator at $0-4{ }^{\circ} \mathrm{C}$ for a maximum of one week. Samples of chilli pepper pods (6 pieces of each variety were used in the experiments) were dried within one week after harvest, when sufficient number of pods had been collected, in the stage of maturity in a laboratory oven with ventilation. Before drying, the chilli peppers were cut into halves or quarters (depending on the size) to speed up drying and to prevent undesired changes (moulds). Chilli peppers were dried along with the placenta and seeds. Drying was carried out in two stages, at $40 \pm 5^{\circ} \mathrm{C}$ in the first phase of 24 hours, and in the second phase for $12-24$ hours, depending upon the water content. After drying, the chilli peppers were stored in a sealed glass container in a dry, dark place until analysis (not more than one month). The water content was determined in individually dried chilli peppers.

\section{HPLC analysis of capsaicin}

HPLC analysis of capsaicin content consisted of sample preparation, extraction and liquid chromatographical analysis.

Sample extraction: fresh and dried material were cut into pieces (all of the pods were mixed and homogenized together after the removal of the placenta and seeds). The extractions were carried out with ethanol at a ratio of $1: 10$, 
sonication at the lasts 30 minutes, and then 4 hours of maceration with an extraction efficiency of $90 \%$.

HPLC analysis: column Ascentis Express RP-Amide $2.7 \mu \mathrm{m}, 100 \times 2.1 \mathrm{~mm}$, gradient acetonitrile: $0.2 \%$ $\mathrm{HCOOH}, 0$ minutes $30: 70$, after 10 minutes $71: 29$, flow rate $0.5 \mathrm{ml} . \mathrm{min}$, injection volume $1 \mu \mathrm{l}$, temperature $40^{\circ} \mathrm{C}$, and UV detection at $254 \mathrm{~nm}$ and $280 \mathrm{~nm}$. Capsaicin content was determined based on a calibration curve and SHU units were determined by calculation.

According to the commonly accepted Scoville organoleptic test, the spicy strength of the samples are calculated by converting the capsaicin content expressed in grams of capsaicin per gram of pepper. This conversion to Scoville heat units is done by multiplying the capsaicin content in the pepper by the coefficient corresponding to the heat value for pure capsaicin and corrected for sample extraction efficiency according to the formula: $18 \times \mu \mathrm{g}$.g.

\section{RESULTS}

The capsaicin content in fresh and dried samples of each chilli pepper was determined on the basis of compliance with the standard of capsaicin using HPLC. Fig. 1 shows a chromatogram of the standard capsaicin determination by HPLC using the optimized conditions described above. The highest peak in the chromatogram represents the standard of capsaicin at a wavelengths of $254 \mathrm{~nm}$ and $280 \mathrm{~nm}$.

Table 1. Weight of fresh and dried chilli peppers and weight loss after drying

\begin{tabular}{lccc}
\hline $\begin{array}{c}\text { Chilli } \\
\text { peppers }\end{array}$ & $\begin{array}{c}\text { Weight of fresh } \\
\text { peppers } \\
\mathbf{6} \text { pcs/ } \varnothing[\mathrm{g}]\end{array}$ & $\begin{array}{c}\text { Weight of dried } \\
\text { peppers } \\
\mathbf{6} \text { pcs/ } \varnothing[\mathrm{g}]\end{array}$ & $\begin{array}{c}\text { Weight loss } \\
{[\%]}\end{array}$ \\
\hline BJ & $24.84 / 4.14$ & $3.35 / 0.56$ & 86.47 \\
HRS & $25.74 / 4.29$ & $3.52 / 0.59$ & 86.47 \\
HY & $29.88 / 4.98$ & $3.42 / 0.57$ & 88.15 \\
HMR & $46.74 / 7.79$ & $6.75 / 1.13$ & 85.49 \\
HT & $22.62 / 3.77$ & $2.71 / 0.45$ & 88.06 \\
HPL & $27.48 / 4.58$ & $3.13 / 0.52$ & 88.65 \\
HR & $49.26 / 8.21$ & $7.25 / 1.21$ & 85.26 \\
\hline
\end{tabular}

BJ - Bhut Jolokia; HRS - Habanero Red Savina; HY — Habanero Yellow; HMR — Habanero Maya Red; HT — Habanero Tasmania; HPL — Habanero Paper Latern; HR — Habanero Red; $\varnothing$ - arithmetic mean
Table 2. Capsaicin concentration in fresh and dried chilli peppers

\begin{tabular}{lcc}
\hline Chilli peppers & $\begin{array}{c}\text { Capsaicin in fresh } \\
\text { chilli peppers } \\
{\left[\mu \mathrm{g} \cdot \mathrm{g}^{-1}\right]}\end{array}$ & $\begin{array}{c}\text { Capsaicin in dried } \\
\text { chilli peppers } \\
{\left[\mu \mathrm{g} \cdot \mathrm{g}^{-1}\right]}\end{array}$ \\
\hline BJ & 3041 & 25944 \\
HRS & 967 & 8215 \\
HY & 522 & 6284 \\
HMR & 275 & 2677 \\
HT & 273 & 2619 \\
HPL & 252 & 2477 \\
HR & 327 & 1128 \\
\hline
\end{tabular}

BJ — Bhut Jolokia; HRS — Habanero Red Savina; HY — Habanero Yellow; HMR - Habanero Maya Red; HT - Habanero Tasmania; HPL — Habanero Paper Latern; HR — Habanero Red

Table 3. Calculated SHU in fresh and dried chilli peppers after correction for extraction yield

\begin{tabular}{ccc}
\hline Chilli peppers & $\begin{array}{c}\text { SHU in fresh } \\
\text { chilli peppers } \\
{\left[18 \times \mu \mathrm{g}^{-1}\right]}\end{array}$ & $\begin{array}{c}\text { SHU in dried } \\
\text { chilli peppers } \\
{[18 \times \mu \mathrm{g} . \mathrm{g}]}\end{array}$ \\
\hline BJ & 54738 & 466992 \\
HRS & 17406 & 147870 \\
HY & 9396 & 113112 \\
HMR & 4950 & 48186 \\
HT & 4914 & 47142 \\
HPL & 4536 & 44586 \\
HR & 5886 & 20304 \\
\hline
\end{tabular}

BJ - Bhut Jolokia; HRS - Habanero Red Savina; HY — Habanero Yellow; HMR - Habanero Maya Red; HT - Habanero Tasmania; HPL — Habanero Paper Latern; HR — Habanero Red

The absorbance for standards of capsaicin have been used in preparation of the calibration curve. The results for the concentration of capsaicin in the analysed samples were calculated using the equation: $\mathrm{y}=0.0009 \mathrm{x}(\mu \mathrm{g})$.

Table 1 shows the weights of fresh and dried peppers $(\mathrm{g})$ calculated as an average of six pods and the weight loss after drying (\%). Habanero Red (HR) had the highest weight of fresh peppers and the lowest mass was found in Habanero Tasmania (HT). After drying, the weight of fresh chilli peppers decreased from $85.26 \%$ to $88.65 \%$. 


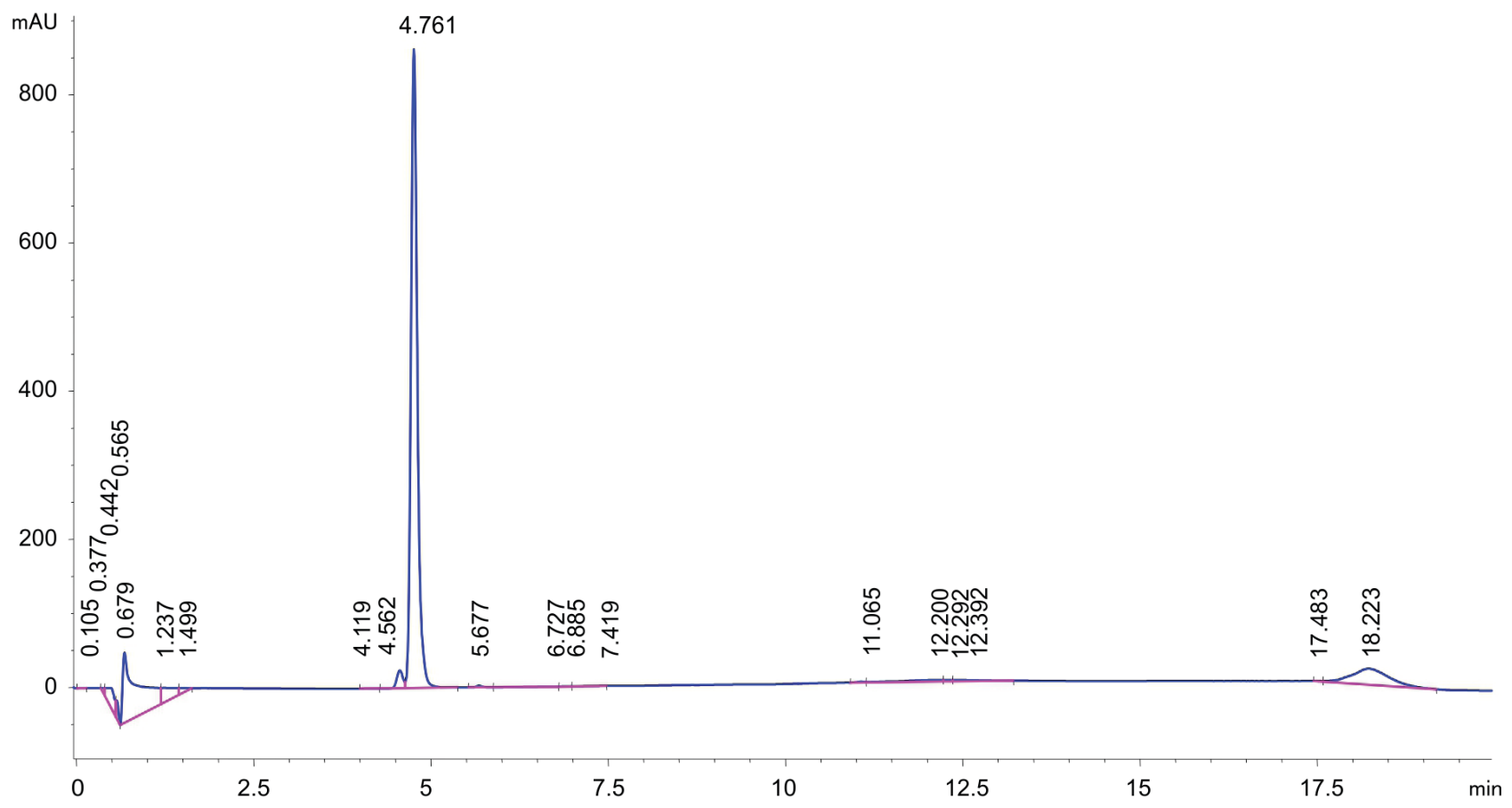

Fig. 1. Chromatogram of capsaicin standard determination using HPLC

In Table 2, fresh and dried chilli peppers are ranked according to capsaicin content expressed as $\mu \mathrm{g} \cdot \mathrm{g}^{-1}$. The capsaicin content increased by drying 4-10 fold compared to fresh chilli peppers.

In Table 3, fresh and dried chilli peppers are ranked according to capsaicin content expressed as SHU units $\left(18 \times \mu \mathrm{g} \cdot \mathrm{g}^{-1}\right)$, calculated from capsaicin concentration given in Table 2 and corrected for the extraction yield (90\%). The content of capsaicin increased by drying 5 to 10 times compared with fresh chilli peppers.

\section{DISCUSSION}

In our study, we compared various Habanero varieties with the Bhut Jolokia variety. The results can be compared with the following study undertaken to compare the heat levels of Habanero Red Savina and Bhut Jolokia in a replicated field trial, i.e., establish whether Bhut Jolokia truly has a higher heat level than Habanero Red Savina. Once the fruit had matured on the plants in the field, a single harvest of 25 random mature fruits from at least 10 plants in each replication was combined. After harvest, the sample was dried and ground. The extraction of the capsaicinoids and the estimation of capsaicinoid amounts followed the high performance liquid chromatography (HPLC) procedures for the short run method as described by Collins et al. [4]. The HPLC data were converted from parts per million to SHU by multiplying the parts per million by 16 [3]. The environment is known to affect the heat level of chilli pepper cultivars [8]. Having a replicated field trial with standard control cultivars allowed for a better comparison of heat levels among cultivars. The results of the analysis for Bhut Jolokia indicated that it possessed an extremely high heat level, 1001304 SHUs, whereas Habanero Red Savina recorded a heat level of 248556 SHUs. Independent tests confirmed this high level of heat for Bhut Jolokia with 927 199SHUs and 879953 SHUs from Southwest BioLaboratories and Ag-Biotech, respectively [3]. These results of Bhut Jolokia heat level have been higher compared to our results. The aim of the next study was to determine the content of capsaicin and dihydrocapsaicin in Capsicum samples collected from city markets in Riyadh (Saudi Arabia), calculate their pungency in Scoville heat units (SHU) and evaluate the average daily intake of capsaicin for the population of Riyadh. The samples consisted of hot chil- 
lies, red chillies, green chillies, green peppers, red peppers and yellow peppers. The extraction of capsaicinoids was done using ethanol as a solvent, while high HPLC was used for separation, identification and quantitation of the components. The limit of detection (LOD) of the method was 0.09 and $0.10 \mu \mathrm{g} \cdot \mathrm{g}^{-1}$ for capsaicin and dihydrocapsaicin, respectively, while the limit of quantification (LOQ) was 0.30 and $0.36 \mu \mathrm{g}$.g for capsaicin and dihydrocapsaicin, respectively. Hot chillies showed the highest concentration of capsaicin $(4249 \pm 190.3 \mu \mathrm{g}$.g) and the highest pungency level (67984SHU) comparable with our results for Bhut Jolokia [1].

Capsaicinoids are mainly ingested as naturally occurring pungency-producing components of Capsicum spices (chilli, cayenne pepper, red pepper). Their concentrations typically range from $100 \mu \mathrm{g} . \mathrm{g}$ in chilli pepper to $2500 \mu \mathrm{g} . \mathrm{g}$ in red pepper [14]. Pepper varieties from Capsicum annuum, $C$. frutescens and $C$. chinense were found to contain 220-20000 $\mu \mathrm{g}$ total capsaicinoids.g dry weight [18]. In another study, cayenne pepper samples had mean capsaicin and dihydrocapsaicin contents of 1320 and $830 \mu \mathrm{g} . \mathrm{g}$ dry weight, respectively [11].

Capsaicinoids are synthesized exclusively in the epidermal cells of the placenta of Capsicum fruits and are accumulated in blisters along the epidermis. Their biosynthesis begins approximately 20 days postanthesis, with a number of enzymes being involved in the biosynthetic pathway. The degree of pungency depends on the Capsicum species and cultivars, and the capsaicin and dihydrocapsaicin contents can be affected by different factors such as the developmental stage of the fruit and the environmental growth conditions [7]. The biosynthesis of capsaicinoids occurs in the placenta, where the specialised epidermal cells accumulate in vacuoles and excrete on the inner surface of the seed and pericarp; therefore, the capsaicinoids should accumulate preferentially in the placenta rather than in the pericarp. Recently, similar studies indicated that capsaicin is mostly located in vesicles or vacuole like sub-cellular organelles of epidermal cells of the placenta in the pod. The highest concentrations of capsaicin was found in the ovary and in the lower flesh (tip) and the lowest content of capsaicin can be found in the seeds. The gland on the placenta of the fruit produces the capsaicinoids. The seeds are not the source of pungency but they occasionally absorb capsaicin because they are in close proximity to the placenta. No other plant part produces capsaicinoids. The majority, about $89 \%$, of the capsaicin is associated with the placental partition of the fruit and nearly $5-6 \%$ in the pericarp and the seed. The composition of capsaicin may vary among different varieties of the same species and with fruit of a single variety [2]. A likely explanation for our finding is that the presence of capsaicinoids in the pericarp suggests that capsaicinoids are translocated from the placenta to the pericarp tissue via the cell walls of the epidermal layer of the placenta. The removing of the placenta and, less likely, environmental factors are obviously the reasons why the capsaicin concentration in our chillies is lower.

Currently, hot air drying is popular for drying chilli due to a relatively short drying time, uniform heating and more hygienic characteristics. The temperature ranges from 45 to $70^{\circ} \mathrm{C}$ (approximately $10 \%$ moisture content), and this reduces drying time to less than $20 \mathrm{hrs}$. This temperature range gives the maximum colour values and minimizes the loss of volatile oils and discolouration. The initial average moisture content of fresh chilli is $85.15 \%$. The average moisture contents of all dried chilli is $11 \%$. Furthermore, the capsaicin content and hotness of dried chilli are higher than in the fresh chilli sample $(\mathrm{P} \leq 0.05)$ [19]. Comparing the capsaicin content in fresh and dried chilli peppers in our study, in dried chilli peppers the content was 4 to 10 times higher than in fresh ones. This was caused by the dehydration of the chilli matrix and improved extractability of capsaicin by cell disruption during the thermal process. On the other hand, there is a study by Topuz and Ozdemir [20] who reported that sun-dried Turkish paprika chilli, which was processed for 5-7 days, lost $24.6 \%$ of the capsaicin content (approximately 12-14\% moisture content). Oven-dried Turkish paprika chilli, which was dehydrated at $70{ }^{\circ} \mathrm{C}$ for $90 \mathrm{~min}$, lost $21.5 \%$ of the capsaicin content. This was due to the temperature, time and drying methods.

\section{CONCLUSIONS}

From a practical point of view, the planting of six varieties of Habanero chilli peppers and Bhut Jolokia was successfully completed. After harvesting the fresh, and then also drying the chilli peppers, they were analysed by HPLC to determine the content of capsaicin. Based on the results, the most pungent chilli pepper is Bhut Jolokia, which has several times higher content of capsaicin ( $54738 \mathrm{SHU}$ ) in fresh, and also dried fruits (466992 SHU) compared to the 
Habanero varieties, in turn was followed in order by, Red Savina, Yellow, Maya Red, Tasmania, Paper Latern, and Red. They were found to have lower values in the content of capsaicin, in contrast to the values reported by other studies. The pungency can be influenced by the weather conditions such as heat and it increases with the maturity of the fruit. The great impact was also post harvesting processing such as removing of the seeds and placenta when capsaicin content is decreased rapidly.

\section{REFERENCES}

1. Al Othman, Z.A., Ahmed, Y.B., Habila, M.A., Ghafar, A. A., 2011: Determination of capsaicin and dihydrocapsaicin in Capsicum fruit samples using high performance liquid chromatography. Molecules, 16, 8919-8929.

2. Arora, R., Gill, N.S., Chauhan, G., Rana, A.C., 2011: An overview about versatile molecule capsaicin. A review article. Int. J. Pharm. Sci. Drug Res., 3, 280-286.

3. Bosland, P. W., Baral, J. B., 2007: Bhut Jolokia - the world's hottest known chile pepper is a putative naturally occurring interspecific hybrid. HortScience, 42, 222-224.

4. Collins, M. D., Wasmund, L. M., Bosland, P. W., 1995: Improved method for quantifying capsaicinoids in Capsicum using high-performance liquid chromatography. HortScience, 30, 137-139.

5. Deal, C. L., Schnitzer, T. J., Lipstein, E., Seibold, J. R., Stevens, R. M., Levy, M. et al., 1999: Treatment of arthritis with topical capsaicin: A double-blind trial. Clin. Ther., 13, 383-395.

6. Fattorusso, E., Taglialatela-Scafati, O., 2008: Modern alkaloids: structure, isolation, synthesis and biology. Weinheim, 73-104.

7. Garces-Claver, A., Arnedo-Andres, M.S., Abadia, J., GilOrtega, R., Alvarez-Fernandez, A., 2006: Determination of capsaicin and dihydrocapsaicin in Capsicum fruits by liquid chromatography-electrospray/time-of-flight mass spectrometry. J. Agric. Food Chem., 54, 9303-9311.

8. Harvell, K. P., Bosland, P.W., 1997: The environment produces a significant effect on pungency of chiles (Capsicum annuum L.). HortScience, 32, 1292.

9. Holzer, P., 1994: Capsaicin: cellular targets, mechanisms of action, and selectivity for thin sensory neurons. Pharmacol. Rev., 43, 143-201.
10. Kempaiah, R.K., Manjunatha, H., Srinivasan, K., 2005: Protective effect of dietary capsaicin on induced oxidation of low-density lipoprotein in rats. Mol. Cell. Biochem., 275, $7-13$.

11. Lopez-Hernandez, J., Oruna-Concha, M. J., Simal-Lozano, J., Gonzales-Castro, M. J., Vazquez-Blanco, M.E., 1996: Determination of capsaicin and dihydrocapsaicin in cayenne pepper and padron peppers by HPLC. Dtsch. Lebensmitt. Rundsch., 92, 393-395.

12. Moore, D. J., Moore, D. M., 2003: Synergistic Capsicum-tea mixtures with anticancer activity. J. Pharm. Pharmacol., 55, 987-994.

13. Nwokem, C.O., Agbaji, E. B., Kagbu, J.A., Ekanem, E. J., 2010: Determination of capsaicin content and pungency level of five different peppers grown in Nigeria. NY Sci. J., 3, 17-21.

14. Parrish, M., 1996: Liquid chromatographic method of determining capsaicinoids in capsicums and their extractives: collaborative study. J. Assoc. Off. Anal. Chem., 79, 738-745.

15. Perucka, I., Oleszek, W., 2000: Extraction and determination of capsaicinoids in fruit of hot pepper Capsicum annuum L. by spectrophotometry and high-performance liquid chromatography. Food Chem., 71, 287-291.

16. Scoville, W. L., 1912: Note on Capsicum. J. Amer. Pharm. Assoc., $1,453$.

17. Szolcsanyi, J., 2004: Forty years in capsaicin research for sensory pharmacology and physiology. Neuropeptides, 38, $377-384$.

18. Thomas, B.V., Schreiber, A.A., Weisskopf, C.P., 1998: Simple method for quantitation of capsaicinoids in peppers using capillary gas chromatography. J. Agric. Food Chem., 46, 2655-2663.

19. Toontom, N., Meenune, M., Posri, W., Lertsiri, S., 2012: Effect of drying method on physical and chemical quality, hotness and volatile flavour characteristics of dried chilli. Int. Food Res. J., 19, 1023-1031.

20. Topuz, A., Ozdemir, F., 2004: Influence of gamma irradiation and storage on the capsaicinoids of sun-dried and dehydrated paprika. Food Chem., 86, 509-515.

21. Zewdie, Y., Bosland, P. W., 2000: Evaluation of genotype, environment, and genotype-by environment interaction for capsaicinoids in Capsicum annuum L. Euphytica, 111, 185-190.

Received January 17, 2017

Accepted April 7, 2017 